\title{
Antibacterial Finishing of Cotton Fabric Using Stinging Nettle (Urtica dioica L.) Plant Leaf Extract
}

\author{
Asnake Ketema (iD and Amare Worku (D) \\ Ethiopian Institute of Textile and Fashion Technology, Bahir Dar University, Bahir Dar, Ethiopia \\ Correspondence should be addressed to Amare Worku; amareworku2005@ddu.edu.et
}

Received 14 January 2020; Revised 22 February 2020; Accepted 31 March 2020; Published 21 April 2020

Academic Editor: Hakan Arslan

Copyright (C) 2020 Asnake Ketema and Amare Worku. This is an open access article distributed under the Creative Commons Attribution License, which permits unrestricted use, distribution, and reproduction in any medium, provided the original work is properly cited.

\begin{abstract}
Natural organic fibers such as cotton, linen, and wool are readily attacked by microorganisms. Microbial growth on a textile fabric causes loss of strength and elongation, discoloration, and changes in appearance. The antibacterial finishing agents extracted from nettle plant leaf have been used to impart finish to the cotton fabric by using the Pad-Dry-Cure application method. The antibacterial activity of the finish was assessed quantitatively using the AATCC 100:2004 test method, and the antibacterial activity against Gram-positive (Staphylococcus aureus) and Gram-negative (Escherichia coli) bacteria was measured. There was a 100 to 99.75 percent reduction in the count of test bacteria. Physical properties of treated and untreated cotton fabrics such as absorbency, fabric stiffness, air permeability, and strength were analyzed. To evaluate the laundering effect of stinging nettle leaf finished fabric, samples were subjected to laundry with 5, 10, 15, 20, 25, 30, 35, and 40 washing cycles using standard AATCC test method 61 , and bacterial count of treated samples was tested. The results showed gradual decrease in antibacterial property, with a 100 to $44 \%$ reduction in the bacterial count for Staphylococcus aureus and a 100 to $30 \%$ reduction in the bacterial count for Escherichia coli. The results of this investigation suggested that nettle leaf, a low-cost abundant plant in Ethiopia, can be used for antibacterial activity in woven cotton fabric.
\end{abstract}

\section{Introduction}

Certain textile material treatments are applied to improve the look and qualities of textile goods. These treatments are called finishes. A finish is a treatment given to a piece of fabric to change appearance, handling/touch, or performance. The purpose is to make the fabric more suitable for its end use. The finishes may be basic or functional. Basic finishes, also called aesthetic finishes, are applied to almost all the fabrics to improve their appearance, feel, and body. Functional finishes are applied to improve the performance of fabric for some specific purpose, for example, fireproof, waterproof, bulletproof, crease-resistant, and antimicrobial finishes [1].

Bacteria, either pathogenic or not, are normally found on human skin, nasal cavities, and other areas, such as the genital area [2, 3]. Typically, pathogenic bacteria like
Escherichia coli and Staphylococcus aureus have been found on textiles [4]. The negative role of microorganisms in the textiles leads the researchers to the development of textiles with antibacterial properties. With this growth in health awareness, many people focused their attention on educating themselves about and protecting themselves from harmful pathogens [5-7]. It soon became more vibrant for antibacterial finished textiles to protect the user from bacteria rather than simply protecting the garment from fiber degradation [8]. Requirements for antimicrobial agents on textiles concern safety (producer and user), wash, and heat fastness and applicability without negative effects on the textile properties.

Besides, antimicrobial textiles should maintain textile properties such as appearance, feel, and durability to laundering as new functional treatment is fabricated because these are important to the consumer. Therefore, new, 
advanced, and innovative technologies are required. Several chemicals have been employed to impart antimicrobial activity to textile goods. Those chemicals embrace inorganic salts, organ metallics, iodophors (substances that slowly release iodine), phenols and thiophenols, antibiotics, heterocyclic and anionic groups and related compounds, formaldehyde derivatives, and amines. Many of these chemicals, however, are toxic to humans; they do not easily degrade in the environment $[9,10]$. Although chemical antimicrobials are effective against a wide range of microbes, they are cause of concern due to the associated side effects and water pollution. The use of synthetic products is becoming increasingly problematic leading to microbial resistance, product withdrawal, undesirable environmental problems, and animal toxicity [11-14]. Hence, there is a great demand for antimicrobial treated textiles based on ecofriendly agents helping to effectively reduce the ill effects associated with microbial growth on textile material $[11,15-20]$. The use of natural plant products for antimicrobial finishing of textile materials has been widely reported. There are vast sources of medicinal plants with active antimicrobial ingredients such as tulsi, pomegranate, and eucalyptus [21]. The research on their use in textiles is very limited and not well documented. These natural products are associated with various benefits like lower incidence of adverse reactions and reduced cost, compared to synthetic pharmaceutical products, and can be exploited as an attractive eco-friendly alternative to synthetic antimicrobial agents for textile applications [22, 23].

Ginkgo-Biloba extract is an eco-friendly antimicrobial agent and its application was investigated in health and medicinal purposes. Due to its nontoxicity characteristics, it is a potential candidate for antimicrobial finishing of institutional textiles range including home accessories, hospital bed sheets, nurses' uniforms, and surgical gowns and drapes. The plant-based natural fruit source was reported for its antimicrobial properties; the fruit-based source is pineapple (Ananas comosus), whose juice was investigated for its activity against harmful microbes. The antimicrobial activity was evaluated through the agar diffusion method. Another plant-based source reported is papaya (Carica papaya) [24, 25]. Berberis vulgaris L. wood as an agricultural waste was used for dyeing and functional finishing of cotton. To facilitate the attachment of natural dye, citric acid was used to create carboxylic acid functional groups on cotton fibers. The dyed sample prepared under the optimum conditions of crosslinking showed good wash and light fastness properties besides very good antibacterial activity against Gram-negative and Gram-positive bacteria [26].

The chitosan and alginate have been used for antimicrobial finishing of textiles. Chitosan is a derivate of chitin; it is water-soluble and cellulose-based. Chitin is a polysaccharide based on amino sugars. In an acid solvent, the amine component turns into a quarterly amino unit that inhibits the growth of microbes. This amino unit works as a shield to block the protein and slow down proliferation by distracting cell membrane; this permits the substance to escape from the bacterial cell, resulting in the death of the bacteria. Antimicrobial activity of chitosan was reported in many studies and it is a widely accepted antimicrobial agent [8]. Several natural agents such as basil (with active agent being eugenol), neem (with active limonoids like azadirachtin, nimbinin), turmeric (curcumin), clove oil, chitosan, sericin, onion, aloe vera, and pomegranate have antimicrobial properties [27, 28].

Natural dye is now fast growing compared to synthetic dye for its safe, healthy, and eco-friendly nature and application. Extraction and utilization of natural pigments have received broad attention in the current years. Kapok flower is an unexplored source of natural dyestuff which can also be utilized for the functionalization of cellulose-based textiles [29]. Kapok flower extract (KFC) was utilized as a functional dye for dyeing of linen fabric in the presence of metallic mordants. The dyed fabrics were assessed for coloration properties (color values, color coordinates, and fastness properties) as well as functional properties such as antibacterial activity, UV protection, and antioxidant activity. The dyed fabrics displayed an excellent antibacterial activity against Gram-positive and Gram-negative bacteria [2].

The coloration of wool by kapok flower extract (KFE) by tannin-based natural mordant using premordanting treating technique could impart important functional properties to the dyed fabrics. Wool fabrics were mordanted using tamarind seed coats extract (TSCE) and further dyed with KFE. The dyed fabrics were evaluated for coloration properties (color values, fastness properties) as well as functional properties like antibacterial and antioxidant activity [30]. Flora forest is a major component that contributes to the natural resources from which natural pigment can be derived. Both silk and wool showed excellent dyeing ability when dyed with the extracted pigments. Fabrics dyed with leaf pigments showed an unchanged or increased colorfastness to light, washing, and storage. This is because the rich content of phenolic hydroxyl within leaf chemical structure is sensitive to light and alkaline condition and can result in a hyperchromic effect [31]. The natural dyes require mordants for their fixation on textile materials. Natural mordants are thus gaining importance in order to get complete-natural dyeing. The natural mordants, namely, hard and tamarind seed coat, and natural dyes like turmeric and henna were extracted using conventional and ultrasound approaches, and various extracts obtained were described in terms of their optical densities. The combinations of mordants/dyes and dyed fabrics were evaluated for their color strength and fastness properties [32].

Stinging nettle (Urtica dioica L.) is grown in many areas across the world annually. It belongs to medicinal herbs [33]. Several findings show that the stinging nettle (Urtica dioica L.) plant contains compounds like alkaloids, phenols, saponins, steroids, tannins, and glycosides which exhibit antimicrobial properties [15]. The leaf extracts of nettle (Urtica dioica) were studied and reported to have excellent antimicrobial activity against microorganisms based on the availability of large amounts of bioactive compounds such as tannins, flavonoids, and alkaloids, which are effective against bacterial and fungal infections [9]. With respect to that, the use of nettle (Urtica dioica) leaf extract as a textile finish on 
cotton fabrics has not been examined and reported in any form.

In the current study, the interaction of extracted components from the nettle plant leaf with cotton fabric using citric acid and their potential antimicrobial efficacy against Staphylococcus aureus and Escherichia coli bacterial species, which are known to cause cross infections in the cotton fabric as well as being responsible for causing unpleasant odors in textiles, were investigated.

\section{Materials and Methods}

2.1. Materials and Apparatus. Citric acid was used as a precursor for the crosslinking agent between extracted powder and fabric. Ethanol $\left(\mathrm{CH}_{3} \mathrm{CH}_{2} \mathrm{OH}, 97 \%\right.$ purity) was prepared according to the procedure needed for the extraction of chemical ingredients from the nettle leaf.

A hundred percent of scoured cotton fabric was used in this study to ensure complete wetting and uniform absorbency of the solution during padding. Scouring treatment was applied to the woven cotton fabric to remove foreign material before imparting antibacterial finish.

The following apparatus was used in this study: ultrasonic extractor, electronic balance, oven dryer, Whatman filter paper No. 1, pH meter, measuring cylinder, Condenser, magnetic stirrer, crucible, muffle furnace, FTIR, TGA, UV spectroscopy, and padding mangle.

2.2. Preparation of Sample. The plant leaf was collected from Amhara region in Debre Tabor, Ethiopia, and washed with pure water, rinsed with distilled water, cleaned, air-dried for 8 days, and cut into small pieces for further size reduction into fine powder with the help of electric grinder up to $0.710 \mu \mathrm{m}$ particle size. Major phenolic chemical ingredients of nettle leaf extract are given in Figure 1.

2.3. Ultrasonic Extraction Technique. Ultrasonic assisted extraction (UAE) method has been considered according to its simplicity to extract the responsible chemical compounds, easy handling, low cost, high yield or efficiency, lower organic extraction solvent consumption, reduced time for extraction, and reliable procedure in an extensive range of organic solvents for various phenolic compounds in largescale level and industry. Air-dried nettle leaf sample, 20 grams, was prepared in $200 \mathrm{ml}, 400 \mathrm{ml}$, and $600 \mathrm{ml}$ of water and $97.5 \%$ ethanol and extracted using ultrasonic extraction techniques for 30,60 , and 90 extraction minutes at $45-50^{\circ} \mathrm{C}$ (Table 1). The extracted ingredient was filtered through a filter paper (Whatman No. 1) which was impregnated with the same solvents. The ethanol was concentrated to near dryness under reduced pressure below $50^{\circ} \mathrm{C}$ using a rotary evaporator machine. The amount of the concentrated ingredient extracted was noted down and stored in air tight glass bottles in a refrigerator until further use [35].

Based on the parameters in Table 2, antibacterial agent was extracted and the number of trials is designed and generated using central composite design (CCD), DesignExpert ${ }^{\circledR}$ version 11 software.
2.4. Quantitative Phytochemical Analysis. The leaf extract that exhibited the maximum antibacterial activity was assessed for the presence of phytochemicals. A preliminary phytochemical analysis was performed to determine the amount of phenolic and flavonoid compounds in milligram per gram of extracted powder [36-38].

2.5. Determination of Total Phenolic Content (TPC). UV-spectrophotometric methods are most commonly used for the quantification of phenolic content. Preparation of standard gallic acid solution was as follows: 0.2 gram of gallic acid was dissolved into $200 \mathrm{ml}$ distilled water, so the concentration of the solution was $0.001 \mathrm{gram} / \mathrm{ml}$ or $1000 \mu \mathrm{g} / \mathrm{ml}$. This is called the stock solution. Then serial dilution was performed in order to prepare different concentrations of the solution $(0 \mathrm{~g} / \mathrm{ml}, 50 \mathrm{~g} / \mathrm{ml}, \quad 100 \mathrm{mg} / \mathrm{ml}, \quad 150 \mathrm{mg} / \mathrm{ml}$, $200 \mathrm{mg} / \mathrm{ml}, 250 \mathrm{mg} / \mathrm{ml}$, and $300 \mathrm{mg} / \mathrm{ml}$ ) which are used for preparing calibration curve.

Estimation of total phenol content in the selected plant extract was measured spectrophotometrically by Folin-Ciocalteu (FCR) colorimetric method, using gallic acid as the standard and expressing results as gallic acid equivalent (GAE) per gram of sample. Different concentrations $(0.01 \mathrm{mg} / \mathrm{ml})$ of gallic acid were prepared in methanol. Aliquots of $1 \mathrm{ml}$ of the test sample and each sample of the standard solution were taken and mixed with $2 \mathrm{ml}$ of Folin-Ciocalteu reagent (1:10 in deionized water) and $4 \mathrm{ml}$ of a saturated solution of sodium carbonate (7.5\% $\mathrm{w} / \mathrm{v})$. The tubes were covered with silver foils and incubated at room temperature for 30 minutes with intermittent shaking. The absorbance was taken at $765 \mathrm{~nm}$ using methanol as blank. All the samples were analyzed in three replications. The total phenolic amount was determined with the help of a standard cure prepared from a pure phenolic standard (gallic acid) [10, 39, 40].

$$
\operatorname{TPC}\left(\frac{\mathrm{mgGAE}}{m}\right)=\frac{C * V}{m} .
$$

A formula was used to assess the phenolic compounds in $\mathrm{mg}$ from one gram of extracted powder; when the TPC amount increases, the antibacterial activity will be effective.

Here, TPC is the total phenol content in mg of gallic acid equivalent per gram of extracted gallic acid equivalent, $m$ is dry mass of a sample in gram used for characterization, $C$ is a concentration of gallic acid in $\mathrm{mg} / \mathrm{l}$, and $V$ is the volume of sample taken in a milliliter.

2.6. Determination of Total Flavonoid Content (TFC). The TFC of the leaf extract was determined by aluminum chloride colorimetric assay. Briefly, $0.5 \mathrm{ml}$ aliquots of the extract and standard solution $(0.01-1.0 \mathrm{mg} / \mathrm{ml})$ of quercetin were added to $2 \mathrm{ml}$ of distilled water and subsequently to $0.15 \mathrm{ml}$ of sodium nitrite $\left(5 \% \mathrm{NaNO}_{2}, \mathrm{w} / \mathrm{v}\right)$ solution and mixed. After 6 minutes, $0.15 \mathrm{ml}$ of $\left(10 \% \mathrm{AlCl}_{3}\right.$, w/v) solution was added. The solutions were allowed to stand for quercetin $6 \mathrm{~min}$, and after that $2 \mathrm{ml}$ of sodium hydroxide $(4 \% \mathrm{NaOH}$, w/v) solution was added to the mixture. The final volume was adjusted to $5 \mathrm{ml}$ with immediate addition of distilled 
<smiles>O=C(O)CC(OC(=O)/C=C/c1ccc(O)c(O)c1)C(=O)O</smiles>

(a)

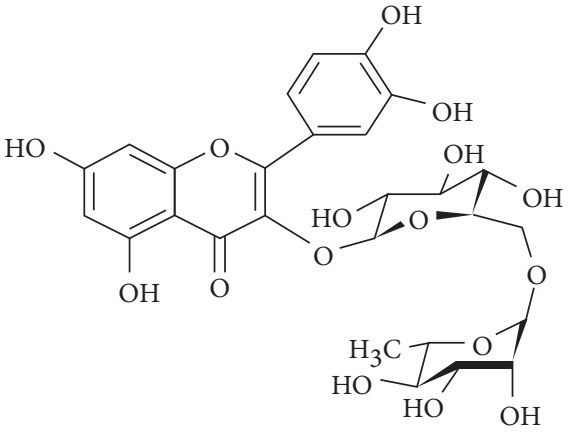

(b)

FIgURE 1: Chemical structures of extracted phenolic compound: (a) 2-O-caffeoylmalic acid, (b) rutin [33, 34].

TABle 1: Antibacterial agent extraction parameters, water and ethanol used as extraction solvents.

\begin{tabular}{lc}
\hline Extraction factors & Parameters \\
\hline Material to liquor ratio & $1: 10,1: 20,1: 30$ \\
Extraction time (minutes) & $30,60,90$ \\
Extraction temperature $\left({ }^{\circ} \mathrm{C}\right)$ & $45-50$ \\
\hline
\end{tabular}

TABLE 2: Number of runs by using central composite design (CCD) and their yield.

\begin{tabular}{lcccc}
\hline & Factor 1 & Factor 2 & \multicolumn{2}{c}{$\begin{array}{c}\text { Response } \\
\text { Yield }(\%)\end{array}$} \\
& Trials & Time (minute) & Conc. (ml/g) & \multicolumn{2}{c}{ Water } & Ethanol \\
\hline 1 & 60 & 20 & 40 & 44 \\
2 & 90 & 10 & 45 & 49 \\
3 & 90 & 30 & 55 & 59 \\
4 & 18 & 20 & 26 & 30 \\
5 & 60 & 34 & 47 & 51 \\
6 & 30 & 30 & 35 & 39 \\
7 & 102 & 20 & 54 & 55 \\
8 & 60 & 20 & 40 & 44 \\
9 & 60 & 20 & 41 & 45 \\
10 & 60 & 6 & 33 & 37 \\
11 & 60 & 20 & 39 & 43 \\
12 & 60 & 20 & 40 & 44 \\
13 & 30 & 10 & 25 & 29 \\
\hline
\end{tabular}

water, mixed thoroughly, and allowed to stand for another $15 \mathrm{~min}$. The absorbance of each mixture was determined at $510 \mathrm{~nm}$ against the same mixture but without leaf extract as a blank. TFC was determined as mg quercetin equivalent per gram of sample with the help of the calibration curve of quercetin. All measurements were performed in triplicate $(n=3)[41]$ :

$$
\operatorname{TFC}\left(\frac{\mathrm{mgQUE}}{m}\right)=\frac{C * V}{m} .
$$

The total flavonoid content of the extracts can be determined using the above formula, where $C$ is the concentration of quercetin in $\mathrm{mg} / \mathrm{L}$ of quercetin equivalence, $V$ is the volume of sample taken $(\mathrm{ml}), m$ is the dry weight of sample (g), and TFC is the total flavonoid content in mg of quercetin equivalence.

2.7. Functional Group and Thermal Analysis. Fourier Transform Infrared (FTIR) Spectrophotometer is the most powerful tool for identifying the types of functional groups based on the wavelength of light absorbed. By interpreting the infrared absorption spectrum, the chemical bonds in a molecule were determined [42].

The TGA curve was obtained with a heating rate of $10^{\circ} \mathrm{C} \mathrm{min}^{-1}$ in the temperature range of 30 to $1000^{\circ} \mathrm{C}$, by using alumina crucibles and samples' mass of about $10 \mathrm{mg}$. The experiments were carried out under the nitrogen atmosphere at a flow rate of $50 \mathrm{ml} \mathrm{min}^{-1}$.

2.8. Application Procedure. Pad-Dry-Cure is most widely used for $100 \%$ scoured cotton fabric. Nettle leaf extracted powder was treated with nine percent on weight of fabric (owf) under room temperature. The treated fabric was passed between the rollers two to three times at a uniform pressure at 1.5 bar for better penetration of finishing agent and to squeeze out excess liquid from the fabric. The fabric was then dried at $110^{\circ} \mathrm{C}$ and cured at $130^{\circ} \mathrm{C}$ in a curing chamber within 3 minutes.

2.9. Antibacterial Test. Antibacterial testing was done by AATCC standard test method 100:2004 for the quantitative valuation of the antibacterial effectiveness of the antimicrobial agents against Gram-positive bacteria (Staphylococcus aureus) and Gram-negative bacteria (Escherichia coli). Assessment of the percent reduction of bacteria was calculated using

$$
R(\%)=\left(\frac{B-A}{B}\right) \times 100 .
$$

$R$ is the percent reduction of bacteria; $A$ is the the number of bacteria recovered from the inoculated treated test, specimen swatches in the jar incubated over the desired contact period; $B$ is the the number of bacteria recovered from the inoculated untreated test, specimen swatches in the jar incubated over the desired contact period microbes and dyed fabric. 
2.10. Wash Durability Test. The treated fabrics were laundered using AATCC test method 61. Laundering was carried out at MLR of $1: 10$ with $0.5 \%$ on weight of fabric of AATCC detergent and 100 steel balls at a temperature of $90^{\circ} \mathrm{C}$ for 30 minutes. The washing cycle was followed by hot rinsing in plain water at $40^{\circ} \mathrm{C}$ for 10 minutes. Finally, the washed swatches were tumble-dried. Since a single wash-dry cycle simulated 8 regular wash cycles, the laundering procedure was repeated $5,10,15,20,25,30,35$, and 40 times to check chemical durability.

\section{Results and Discussion}

3.1. Yield of Extraction Using Water and Ethanol. The experimental results (Table 2) can be illustrated by the following linear equation:

$$
\begin{aligned}
& \text { Yield }=10.15076+0.33 \text { time }+0.497487 \text { conc. } \\
& \text { Yield }=14.98065+0.31 \text { Time }+0.497487 \text { Conc. } .
\end{aligned}
$$

Equations (4) and (5) depict the yield that has a linear relationship with the factor of extraction time and concentration of water and ethanol used as extraction solvent, respectively.

The actual value and model prediction value of the yield showed a good correlation (Figure 2). Based on the ANOVA analysis, the linear equation has a $p$-value of $0.0001(<0.05)$ indicating that the equation model is significant.

3.2. Analysis of Variance (ANOVA). The results of the ANOVA analysis, factors $\mathrm{A}$ and $\mathrm{B}$, had a significant effect (Tables 3 and 4). The factors A and B had a $p$-value of 0.0001 and 0.0001 , respectively. The model showed that the factors $A$ and $B$ had a positive effect on the extraction yield indicating an increase in these factors; extraction yield increases (Figure 3).

3.3. Optimization Extraction Parameters. The optimum conditions are based on the resulting desirability value. The goal of extraction is to minimize extraction time, concentration, and maximum water and ethanol extraction yield as shown in Tables 5 and 6 , respectively. The optimization process was performed by establishing the highest level of extraction yield.

Table 7 shows that the optimal extraction time is 59 minutes with concentration of $10 \mathrm{ml} / \mathrm{g}$; the predictive yield is 34.991 percent. Ethanolic extraction yield has optimal extraction time of 59.026 minute with concentration of $10.458 \mathrm{ml} / \mathrm{g}$; the predictive yield is 38.716 percent (Table 8).

3.4. Quantitative Analysis of Phytochemical Ingredients. The amount of total phenol content in the extract was determined by the Folin-Ciocalteau reagent described in the Materials and Methods section, using gallic acid as the standard. The absorbance values obtained at different concentrations of gallic acid were used for the construction of a calibration curve. It appeared that the extraction of nettle plant leaf total phenolic content is $27.819 \pm 0.131 \mathrm{mg}$ GAE/g dry weight (equation (1)). The total flavonoid content in the extract of nettle plant leaves is $2.566 \pm 0.227 \mathrm{mg} \mathrm{GAE} / \mathrm{g}$ dry weight (equation (2)) [43-46].

FTIR studied in extracted nettle leaf displayed strong absorption peaks at $3078.19 \mathrm{~cm}^{-1}, 1549.29 \mathrm{~cm}^{-1}, 1405.09 \mathrm{~cm}^{-1}$, and $1077.81 \mathrm{~cm}^{-1}$. The broad peak between $3500 \mathrm{~cm}^{-1}$ and $2500 \mathrm{~cm}^{-1}$ corresponds to a strong $\mathrm{O}-\mathrm{H}$ stretch vibration, which indicates the presence of hydroxyl groups in nettle leaf extract. On finger print region, a doublet band is present between $1390 \mathrm{~cm}^{-1}$ and $1310 \mathrm{~cm}^{-1}$ representing $\mathrm{O}-\mathrm{H}$ bending which indicates phenolic compounds. The FTIR spectra of the treated and untreated cotton fabric were almost the same, and slight differences were at wave number $3000-2500 \mathrm{~cm}^{-1}$. The treated fabric has $\mathrm{O}-\mathrm{H}$ stretch vibration and $\mathrm{OH}$ functional group between 3000 and $2500 \mathrm{~cm}^{-1}$ (Figure 4(a)).

The TGA curves of the crude extract showed that a small weight loss was found in the range of $90-162^{\circ} \mathrm{C}$ due to the evaporation of the humidity of the materials or volatile compounds. $162-537^{\circ} \mathrm{C}$ was associated with aliphatic phenolic compounds decomposition or degradation. Char formation was detected between 537 and $1028^{\circ} \mathrm{C}$ by further extending the analysis temperature (Figure 4(b)).

3.5. Effect of Tensile Strength. The tensile strength of the PadDry-Cure treated cotton fabric decreased by 0.66 and 1.17 percent compared to the untreated control in warp and weft direction, respectively.

Other physical properties such as permeability, stiffness strength, and absorbency were tested accordingly based on ASTM, ISO, and AATCC standard, respectively [33, 47].

3.6. Reaction Mechanisms. The two carboxylic groups of the citric acid are linked with the hydroxyl part of the cellulose and with extracted phenol through covalent bond (Figure 5). Their effective antibacterial activity and phenolic compounds were attached to cotton fabric using citric acid as a crosslinker. Phenolic compounds are among the major and diverse groups of active compounds in the nettle plant leaf. Cotton fabrics treated with phenolic compounds showed excellent antibacterial activity against the Gram-positive bacteria Staphylococcus aureus as well as the Gram-negative bacteria Escherichia coli.

3.7. Antibacterial Activity. The Pad-Dry-Cure treated fabric exhibited maximum antibacterial activity against Gramnegative test organisms compared to the Gram-positive test organisms. Maximum bacteria reduction was observed against Staphylococcus aureus and Escherichia coli. when the padding mangle was applied at a pressure of 1.5 bar with 20,30, and 40 minutes of wetting time. This result demonstrated that the higher the wetting time (30 minutes and 40 minutes) in padding, the better the antibacterial properties. At lower wetting time, 20 minutes, the antibacterial property is low as compared to the other wetting 


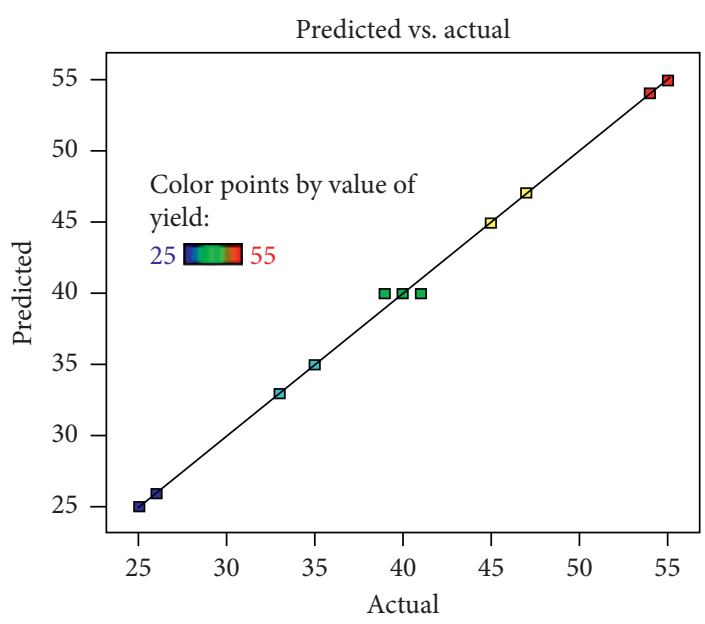

(a)

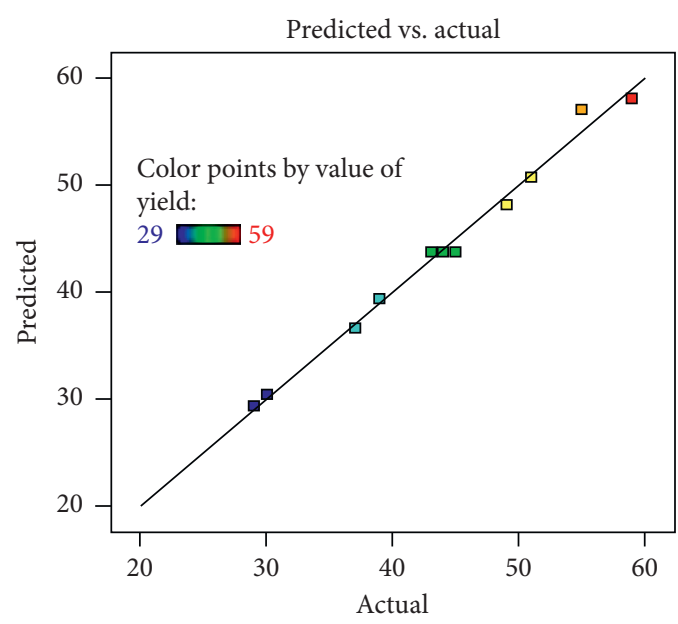

(b)

FIgURE 2: Correlation between actual value and predicted value of (a) water and (b) ethanol extraction yield.

TABLE 3: Analysis of variance (ANOVA) of the water extraction yield.

\begin{tabular}{lccccc}
\hline Source & Sum of squares & DF & Mean square & $F$-value & $p$-value \\
\hline Model & 989.97 & 2 & 494.99 & 2444.08 & $<0.0001$ \\
A: time & 791.98 & 1 & 791.98 & 3910.52 & $<0.0001$ \\
B: conc. & 197.99 & 1 & 197.99 & 977.63 & $<0.0001$ \\
Residual & 2.03 & 10 & 0.2025 & & Significant \\
Lack of fit & 0.0253 & 6 & 0.0042 & 0.0084 & Not significant \\
Pure error & 2.00 & 4 & 0.5000 & & \\
Cor total & 992.00 & 12 & & & \\
\hline
\end{tabular}

TABLE 4: Analysis of variance (ANOVA) of the ethanol extraction yield.

\begin{tabular}{lccccc}
\hline Source & Sum of squares & DF & Mean square & $F$-value & $p$-value \\
\hline Model & 907.80 & 2 & 453.90 & 533.41 & $<0.0001$ \\
A: time & 709.80 & 1 & 709.80 & 834.15 & $<0.0001$ \\
B: conc. & 197.99 & 1 & 197.99 & 232.68 & $<0.0001$ \\
Residual & 8.51 & 10 & 0.8509 & & Significant \\
Lack of fit & 6.51 & 6 & 1.08 & 2.17 & 0.2367 \\
Pure error & 2.00 & 4 & 0.5000 & & Not significant \\
Cor total & 916.31 & 12 & & & \\
\hline
\end{tabular}

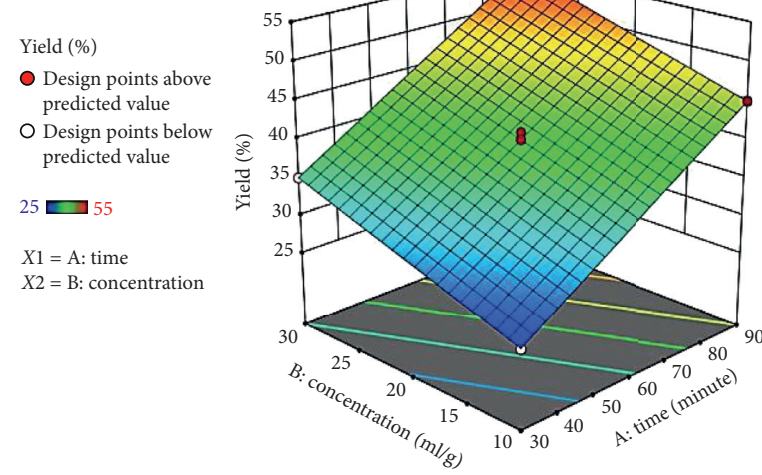

(a)

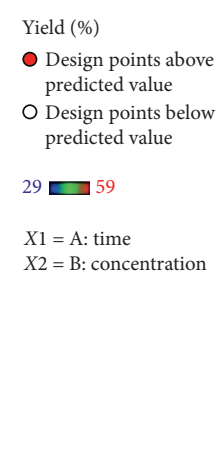

O Design points above predicted value predicted value

$X 1=$ A: time $\mathrm{X} 2=\mathrm{B}$ : concentration

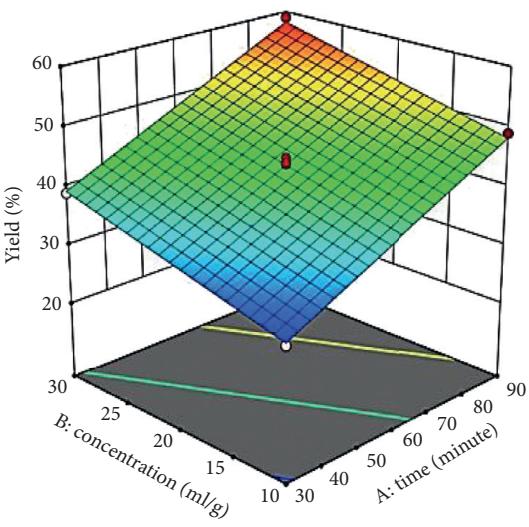

(b)

FIGURE 3: Interaction of factors time and temperature on (a) water and (b) ethanol extraction yield. 
TABLE 5: Constraints of water extraction yield.

\begin{tabular}{|c|c|c|c|c|c|c|}
\hline Name & Goal & Lower limit & Upper limit & Lower weight & Upper weight & Importance \\
\hline A: time & Minimize & 30 & 90 & 1 & 1 & 3 \\
\hline B: conce. & Minimize & 10 & 30 & 1 & 1 & 3 \\
\hline Yield & Maximize & 25 & 55 & 1 & 1 & 3 \\
\hline
\end{tabular}

TABLE 6: Constraints of ethanol extraction yield.

\begin{tabular}{llccccc}
\hline Name & Goal & Lower limit & Upper limit & Lower weight & Upper weight & Importance \\
\hline A: time & Minimize & 30 & 90 & 1 & 1 & 3 \\
B: conc. & Minimize & 10 & 30 & 1 & 1 & 3 \\
Yield & Minimize & 29 & 59 & 1 & 1 \\
\hline
\end{tabular}

TABle 7: Optimization at minimum time, concentration, and high yield.

\begin{tabular}{|c|c|c|c|c|c|}
\hline Number & Time $(\min )$ & Conc. $(\mathrm{ml} / \mathrm{g})$ & Yield (\%) & Desirability & \\
\hline 1 & 59.896 & 10.000 & 34.991 & 0.551 & Selected \\
\hline
\end{tabular}

TABLe 8: Optimization at minimum time, concentration, and high yield.

\begin{tabular}{lcccc}
\hline Number & Time $(\mathrm{min})$ & Concentration $(\mathrm{ml} / \mathrm{g})$ & Yield & Desirability \\
\hline 1 & 59.026 & 10.458 & 38.716 & 0.547
\end{tabular}

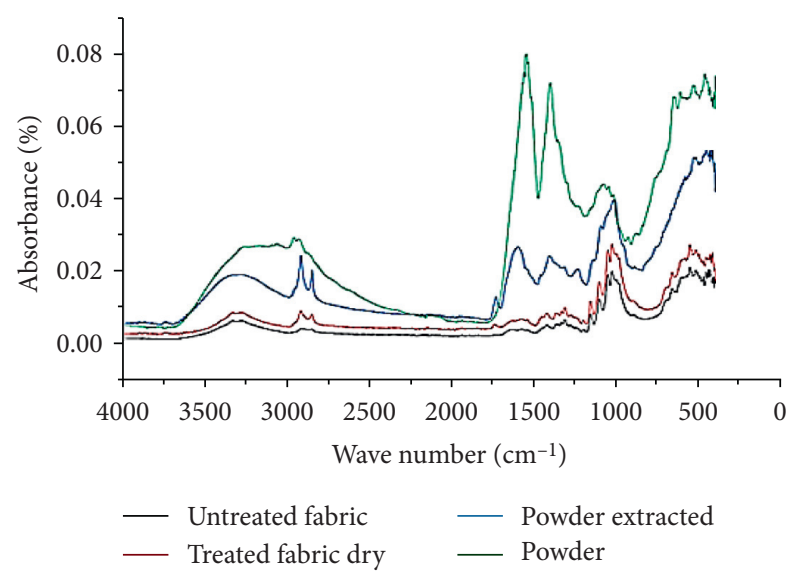

(a)

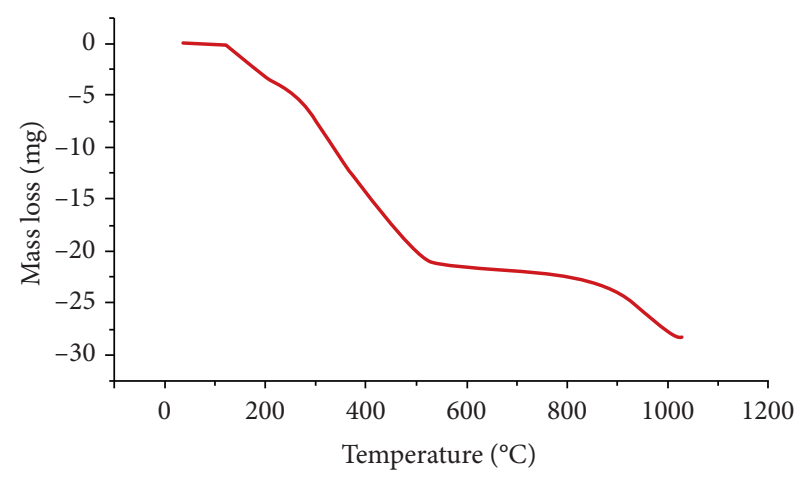

(b)

FIGURE 4: Functional group and thermal analysis of nettle leaf extracted powder: (a) combined FTIR spectra of untreated cotton fabric; (b) thermography resulting from TGA analysis, obtained under a nitrogen flow of $50 \mathrm{ml} / \mathrm{min}$ and heating rate of $10^{\circ} \mathrm{C} / \mathrm{min}$.

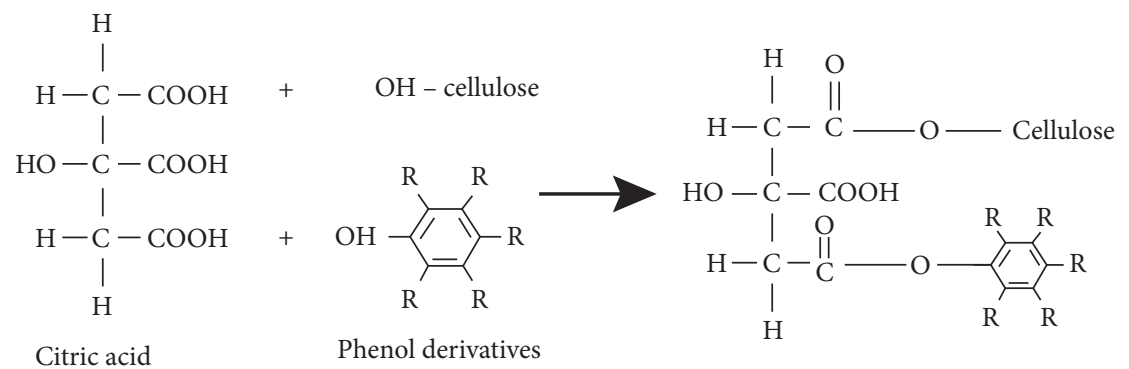

Figure 5: Mechanism of reaction between cellulose, citric acid, and phenolic compounds [48]. 
Table 9: Bacterial reduction test on the Pad-Dry-Cure treated fabric.

\begin{tabular}{lccc}
\hline No. & Wetting time (min.) & \multicolumn{2}{c}{ Bacteria reduction (\%) } \\
\hline 1 & 20 & Staphylococcus aureus & Escherichia coli \\
2 & 30 & 100 & 99.75 \\
3 & 40 & 100 & 100 \\
\hline
\end{tabular}

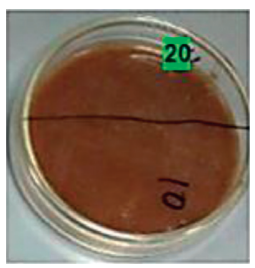

S. aureus

Soaking time-20 minutes

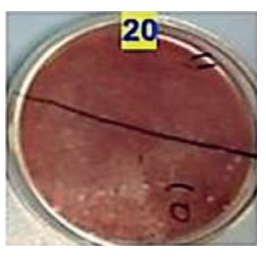

E. coli

Soaking time-20 minutes

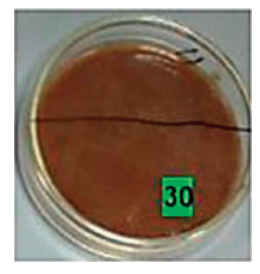

S. aureus

Soaking time-30 minutes

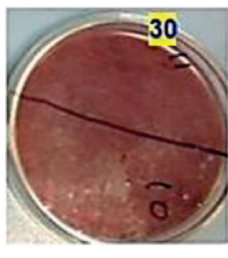

E. coli

Soaking time-30 minutes

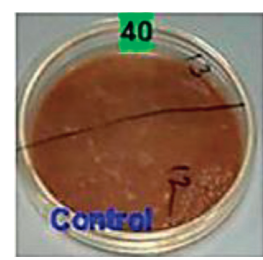

S. aureus

Soaking time-40 minutes

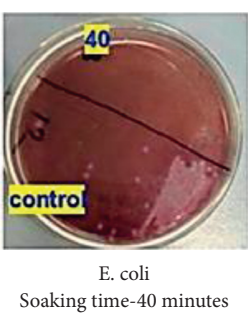

Figure 6: The test results of Pad-Dry-Cure antibacterial treated fabric for Staphylococcus aureus and Escherichia coli.

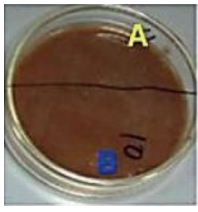

After 5 wash

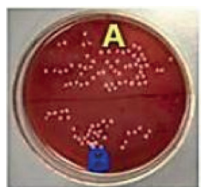

After 25 wash

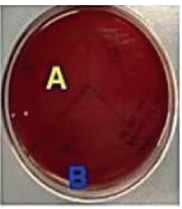

After 10 wash

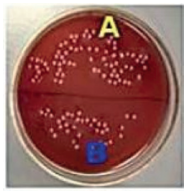

After 30 wash

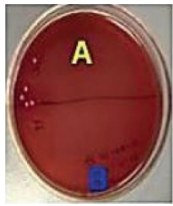

After 15 wash

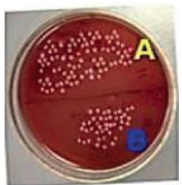

After 35 wash

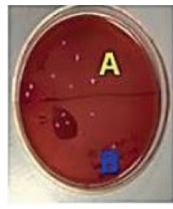

After 20 wash

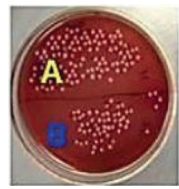

After 40 wash

FIgURE 7: The test results of wash durability for the treated fabrics (note: A: Escherichia coli; B: Staphylococcus aureus).

time. This effect could be becuase the longer the wetting time of each particle of the extracted agents, the deeper the penetration inside the cotton fiber and the better the durability (Table 9, Figure 6).

3.8. Durability to Laundering. Generally, the finished scoured cotton fabric, subjected to number of wash cycles (5, $10,15,20,25,30,35$, and 40 ), showed a gradual decrease in antibacterial property with 100 to $44 \%$ reduction in the bacterial count for Staphylococcus aureus and 100 to $30 \%$ reduction in the bacterial count for Escherichia coli (Figure 7).

Citric acid as a crosslinking agent was added to the antibacterial finishing solutions. It was found that the citric acid was fairly effective against bacteria. Adding polycarboxylic acids to the antibacterial finishing recipes will enhance the durability of many laundering cycles.

\section{Conclusion}

Natural and eco-friendly antibacterial finishing of textiles, a strong antibacterial finishing of textile substrates, with good fastness and stability, was obtained with nettle leaf extract crosslinking on cotton fabrics using citric acid. It exhibits higher antibacterial efficiency. There was a 100 to 99.75 percent reduction in the count of test bacteria after Pad-Dry-Cure treatment of the scoured cotton fabrics with the dry nettle leaf extracted with optimized variables. The optimization of the Pad-Dry-Cure conditions for finishing 
was assessed for bacterial reduction test against Escherichia coli and Staphylococcus aureus. Maximum bacterial reduction percentage was observed against Staphylococcus aureus and Escherichia coli when the wetting time was 30 and 40 minutes.

\section{Data Availability}

The authors have annotated the entire data building process, the empirical techniques presented in the paper, and the number of runs generated using Design-Expert and Minitab 18 software for optimization and analyzation based on their parameters. All data used to support the findings of this study are included within the paper.

\section{Conflicts of Interest}

Asnake Ketema is currently working as a lecturer in textile chemistry at Dire Dawa Institute of Technology, Dire Dawa University, Dire Dawa, Ethiopia. Amare Worku is currently working as lecturer in textile chemistry and School Dean of the School of Textile, Apparel and Fashion Design at Dire Dawa Institute of Technology, Dire Dawa University, Dire Dawa, Ethiopia. The authors declare that there are no conflicts of interest regarding the publication of this paper.

\section{Acknowledgments}

The authors would like to thank their advisor Dr. G. Nalankilli, professor of textile chemistry, for his support, invaluable guidance, and constructive criticism during thesis work and Dr. Tamrat Tesfaye, the secretary of the committee, for his encouragement and hard questions. This work would not have been possible without the financial support of the Ethiopian Institute of Textile and Fashion Technology (EiTEX) only for research work.

\section{References}

[1] A. Kalia, B. Joshi, and M. Mukhija, "Pharmacognostical review of Urtica dioica L." International Journal of Green Pharmacy (IJGP), vol. 8, no. 4, pp. 1998-4103, 2014.

[2] J. Sheikh, N. Singh, and M. Srivastava, "Functional dyeing of cellulose-based (linen) fabric using Bombax ceiba (kapok) flower extract," Fibers and Polymers, vol. 20, no. 2, pp. 312319, 2019.

[3] L. Qian, "Application of nanotechnology for high performance textiles," Journal of Textile and Apparel, Technology and Management, vol. 4, no. 1, pp. 1-7, 2004.

[4] C. K. Kang, S. S. Kim, S. Kim et al., "Antibacterial cotton fibers treated with silver nanoparticles and quaternary ammonium salts," Carbohydrate Polymers, vol. 151, pp. 1012-1018, 2016.

[5] J. E. Herrera, "Synthesis of nanodispersed oxides of vanadium, titanium, molybdenum, and tungsten on Mesoporous silica using atomic layer deposition," Topics in Catalysis, vol. 39, no. 3-4, pp. 245-255, 2006.

[6] J. Hudec, M. Burdová, L. u. Kobida et al., "Antioxidant capacity changes and phenolic profile of Echinacea purpurea, nettle (Urtica dioica L.), and dandelion (Taraxacum officinale) after application of polyamine and phenolic biosynthesis regulators," Journal of Agricultural and Food Chemistry, vol. 55, no. 14, pp. 5689-5696, 2007.

[7] N. A. Ibrahim, M. H. Abo-Shosha, M. A. Gaffar, A. M. Elshafei, and O. M. Abdel-Fatah, "Antibacterial properties of ester-cross-linked cellulose-containing fabrics post-treated with metal salts," Polymer-Plastics Technology and Engineering, vol. 45, no. 6, pp. 719-727, 2006.

[8] G. Thilagavathi and S. K. Bala, "Microencapsulation of herbal extracts for microbial resistance in healthcare textiles," Journal of Fiber and Textile Research, vol. 32, no. 1, pp. 351354, 2007.

[9] N. A. Salih, "Antibacterial effect of nettle (Urtica dioica)," AlQadisiyah Journal of Veterinary Medicine Sciences, vol. 13, no. 1, p. 1, 2014.

[10] K. K. Ghaima, N. M. Hashim, and S. A. Ali, "Antibacterial and antioxidant activities of ethyl acetate extract of nettle (Urtica dioica) and dandelion (Taraxacum officinale)," Journal of Applied Pharmaceutical Science, vol. 3, no. 5, p. 96, 2013.

[11] T. L. Vigo, Protection of Textiles from Biological Attack, Woodhead Publishing, Sawston, UK, 1st edition, 2005.

[12] S. Hashemikia and M. Montazer, "Sodium hypophosphite and nano $\mathrm{TiO}_{2}$ inorganic catalysts along with citric acid on textile producing multi-functional properties," Applied Catalysis A: General, vol. 417-418, pp. 200-208, 2012.

[13] M. Montazer and M. G. Afjeh, "Simultaneous x-linking and antimicrobial finishing of cotton fabric," Journal of Applied Polymer Science, vol. 103, no. 1, pp. 178-185, 2007.

[14] R. Aladpoosh and M. Montazer, "The role of cellulosic chains of cotton in biosynthesis of $\mathrm{ZnO}$ nanorods producing multifunctional properties: mechanism, characterizations and features," Carbohydrate Polymers, vol. 126, pp. 122-129, 2015.

[15] P.S. Vankar, "Antibacterial and antioxidant activities of ethyl acetate extract of nettle (Urtica dioica) and dandelion (Taraxacum officinale)," Journal of Applied Pharmaceutical Science, vol. 3, pp. 096-099, 2013.

[16] T. Nithya, J. Jayanthi, and M. Ragunathan, "Antioxidant activity, total phenol, flavonoid, alkaloid, tannin, and saponin contents of leaf extracts of Salvinia molesta DS Mitchell," Asian Journal of Pharmaceutical and Clinical Research, vol. 9, no. 1, pp. 200-203, 2016.

[17] R. Roghini and K. J. Vijayalakshmi, "Phytochemical screening, quantitative analysis of flavonoids and minerals in ethanolic extract of citrus paradisi," International Journal of Pharmaceutical Sciences and Research, vol. 9, no. 11, pp. 4859-4864, 2018.

[18] F. Sidaoui, "Study of Tunisian nettle leaves (Urtica dioica L.): mineral composition and antioxidant capacity of their extracts obtained by maceration and supercritical fluid extraction," International Journal of Pharmacognosy and Phytochemical Research, vol. 7, pp. 707-713, 2015.

[19] B. Simoncic and B. Tomsic, "Structures of novel antimicrobial agents for textiles-a review," Textile Research Journal, vol. 80, no. 16, pp. 1721-1737, 2010.

[20] G. Sun and S. D. Worley, "Chemistry of durable and regenerable biocidal textiles," Journal of Chemical Education, vol. 82, no. 1, p. 60, 2005.

[21] P. Jaswal, S. AgyaPreet, and G. J. Goel, "Antimicrobial activity of herbal treated cotton fabric," International Research Journal of Engineering and Technology, vol. 4, no. 8, pp. 39-43, 2017.

[22] M. Sathianarayanan, "Antibacterial finish for cotton fabric from herbal products," Indian Journal of Fiber and Textile Research, vol. 35, pp. 50-58, 2010. 
[23] D. Kut, "Effects of environmental conditions on the antibacterial activity of treated cotton knits," AATCC Review, vol. 5, no. 3, 2005.

[24] N. Afraz, "Antimicrobial finishes for textiles," Including results for Curr Trends Fashion Technology Textile Engineering, vol. 5, p. 4, 2019.

[25] A. El-Shafei, "Herbal extract as an ecofriendly antibacterial finishing of cotton fabric," Egyptian Journal of Chemistry, vol. 61, no. 2, pp. 317-327, 2018.

[26] A. Haji, M. Nasiriboroumand, and S. S. Qavamnia, "Cotton dyeing and antibacterial finishing using agricultural waste by an eco-friendly process optimized by response surface methodology," Fibers and Polymers, vol. 19, no. 11, pp. 2359-2364, 2018.

[27] A. Reshma, V. B. Priyadarisini, and K. Amutha, "Sustainable antimicrobial finishing of fabrics using natural bioactive agents," International Journal of Life Science, vol. 4, pp. 10-20, 2018.

[28] W. Ibrahim, "Aloe vera leaf gel extract for antibacterial and softness properties of cotton," Journal of Textile Science \& Engineering, vol. 7, no. 301, p. 2, 2017.

[29] P. S. Vankar, R. Shanker, and S. Wijayapala, "Dyeing of cotton, wool and silk with extract of Allium cepa," Pigment \& Resin Technology, vol. 38, no. 4, pp. 242-247, 2009.

[30] G. Singh, "Functionalization of wool fabric using kapok flower and bio-mordant," Sustainable Chemistry and Pharmacy, vol. 14, pp. 2352-5541, 2019.

[31] K. Gong, Y. Pan, L. J. Rather et al., "Natural pigment during flora leaf senescence and its application in dyeing and UV protection finish of silk and wool-a case study of Cinnamomum camphora," Dyes and Pigments, vol. 166, pp. 114-121, 2019.

[32] J. Sheikh, "Ultrasound assisted extraction of natural dyes and natural mordants vis a vis dyeing," Fibers and Polymers, vol. 17, no. 5, pp. 738-743, 2016.

[33] K. Koszegi, "Antimicrobial Effects of the stinging nettle (Urtica dioica L.)," Analecta Technical Szegedinensia, vol. 11, p. 22, 2017.

[34] K. Belay and M. J. C. M. R. Sisay, "Phytochemical constituents and physicochemical properties of medicinal plant (Moringa oleifera) around Bule Hora," Chemistry and Materials Research, vol. 6, no. 7, pp. 61-72, 2014.

[35] K. Murugesh Babu and K. B. Ravindra, "Bioactive antimicrobial agents for finishing of textiles for health care products," The Journal of the Textile Institute, vol. 106, no. 7, pp. 706-717, 2015.

[36] I. Gülçin, "Antioxidant, antimicrobial, antiulcer and analgesic activities of nettle (Urtica dioica L.)," Journal of Ethnopharmacology, vol. 90, no. 2-3, pp. 205-215, 2004.

[37] P. Mantecca, E. Moschini, P. Bonfanti et al., "Toxicity evaluation of a new $\mathrm{Zn}$-doped $\mathrm{CuO}$ nanocomposite with highly effective antibacterial properties," Toxicological Sciences, vol. 146, no. 1, pp. 16-30, 2015.

[38] V. K. Midha, A. Dakuri, and V. Midha, "Studies on the properties of nonwoven surgical gowns," Journal of Industrial Textiles, vol. 43, no. 2, pp. 174-190, 2013.

[39] S. W. Ali, S. Rajendran, and M. Joshi, "Synthesis and characterization of chitosan and silver loaded chitosan nanoparticles for bioactive polyester," Carbohydrate Polymers, vol. 83, no. 2, pp. 438-446, 2011.

[40] G. M. L. Bearman, A. Rosato, K. Elam et al., "A crossover trial of antimicrobial scrubs to reduce methicillin-resistant Staphylococcus aureus burden on healthcare worker apparel,"
Infection Control \& Hospital Epidemiology, vol. 33, no. 3, pp. 268-275, 2012.

[41] F. Eser and A. Onal, "Dyeing of wool and cotton with extract of the nettle (Urtica dioica L.) leaves," Journal of Natural Fibers, vol. 12, no. 3, pp. 222-231, 2015.

[42] G. Bag, "Assessment of total flavonoid content and antioxidant activity of methanolic rhizome extract of three Hedychium species of Manipur valley," International Journal of Pharmaceutical Sciences, vol. 30, no. 1, pp. 154-159, 2015.

[43] S. Đurović, "Chemical composition of stinging nettle leaves obtained by different analytical approaches," Journal of Functional Food, vol. 32, pp. 18-26, 2017.

[44] C. S. Ezeonu and C. M. Ejikeme, "Qualitative and quantitative determination of phytochemical contents of indigenous Nigerian softwoods," New Journal of Science, vol. 56, Article ID 5601327, 9 pages, 2016.

[45] H. Y. Fu, S. J. Chen, R. F. Chen, W. H. Ding, L. L. Kuo-Huang, and R. N. Huang, "Identification of oxalic acid and tartaric acid as major persistent pain-inducing toxins in the stinging hairs of the nettle, Urtica thunbergiana," Annals of Botany, vol. 98, no. 1, pp. 57-65, 2006.

[46] Y. Gao and R. Cranston, "Recent advances in antimicrobial treatments of textiles," Textile Research Journal, vol. 78, no. 1, pp. 60-72, 2008.

[47] S. W. Ali, "Antibacterial properties of aloe vera gel-finished cotton fabric," Cellulose, vol. 21, no. 3, pp. 2063-2072, 2014.

[48] M. Gupta, S. Thakur, A. Sharma, and S. Gupta, "Qualitative and quantitative analysis of phytochemicals and pharmacological value of some dye yielding medicinal plants," Oriental Journal of Chemistry, vol. 29, no. 2, pp. 475-481, 2013. 